Direct Methods for Limit States in Structures and Materials 
Konstantinos Spiliopoulos • Dieter Weichert Editors

\section{Direct Methods for Limit States in Structures and Materials}

量 Springer 


\section{Editors}

Konstantinos Spiliopoulos

School of Civil Engineering,

Department of Structural Engineering

National Technical University of Athens

Athens, Greece

\author{
Dieter Weichert \\ Institute of General Mechanics \\ RWTH-Aachen University \\ Aachen, Germany
}

ISBN 978-94-007-6826-0

ISBN 978-94-007-6827-7 (eBook)

DOI 10.1007/978-94-007-6827-7

Springer Dordrecht Heidelberg New York London

Library of Congress Control Number: 2013947157

(C) Springer Science+Business Media Dordrecht 2014

This work is subject to copyright. All rights are reserved by the Publisher, whether the whole or part of the material is concerned, specifically the rights of translation, reprinting, reuse of illustrations, recitation, broadcasting, reproduction on microfilms or in any other physical way, and transmission or information storage and retrieval, electronic adaptation, computer software, or by similar or dissimilar methodology now known or hereafter developed. Exempted from this legal reservation are brief excerpts in connection with reviews or scholarly analysis or material supplied specifically for the purpose of being entered and executed on a computer system, for exclusive use by the purchaser of the work. Duplication of this publication or parts thereof is permitted only under the provisions of the Copyright Law of the Publisher's location, in its current version, and permission for use must always be obtained from Springer. Permissions for use may be obtained through RightsLink at the Copyright Clearance Center. Violations are liable to prosecution under the respective Copyright Law.

The use of general descriptive names, registered names, trademarks, service marks, etc. in this publication does not imply, even in the absence of a specific statement, that such names are exempt from the relevant protective laws and regulations and therefore free for general use.

While the advice and information in this book are believed to be true and accurate at the date of publication, neither the authors nor the editors nor the publisher can accept any legal responsibility for any errors or omissions that may be made. The publisher makes no warranty, express or implied, with respect to the material contained herein.

Printed on acid-free paper

Springer is part of Springer Science+Business Media (www.springer.com) 


\section{Foreword}

In the history of structural engineering, safety with respect to collapse, rather than stress admissibility, turns out to be the main worry of several pioneers. In the eighteenth century the Saint Peter dome in Rome and the highest spire of the Milan cathedral (with the "Madonnina" on its top) have been structures investigated for restoration (by Poleni and Boscovich, respectively, both primarily mathematicians) from a standpoint and by a graphical-computational procedure which can be regarded as anticipations of limit analysis methods.

Another memorable event might be regarded as a contribution of limit structural analysis to the solution of crucial social problems: the design of the Morison shelters for protection of British families against V2 bombs during one of the most tragic periods of the Second World War; such design was due to the research team of Sir John Baker in Cambridge. In those years, early forties, two other circumstances occurred in the United States with consequences fruitful also for the development of the direct methods: at Brown University, Providence RI, the successful research stream on structural mechanics centered on plasticity was starting under the guidance of Prager; almost simultaneously, linear (and later nonlinear) mathematical programming was developed in Stanford, by George Dantzing and his team, initially in terms of algorithms for optimization of American navy strategies. Later a productive convergence occurred between mathematical programming and elastoplastic structural mechanics, particularly as for direct methods and their practical applications.

Limit analysis and its generalization to shakedown analysis after the mid of the last century have been one of the most fruitful developments of structural mechanics, simultaneously and interactively with another fast growth in applied science, namely finite element and other methods for computer simulations of physical phenomena, particularly of inelastic responses of structures to external actions.

Each important scientific research area exhibits a flourishing era, characterized by intensive activities and fast growth. Such era for direct methods of limit and shakedown analyses grew with contributions provided by several internationally acknowledged research leaders; obviously they are well known to all research workers in applied mechanics and, therefore, they are not considered in this brief foreword. Here I take the liberty to mention with gratitude only some of them, with whom 
I had opportunities of personal meetings and pleasant interactions before our international scientific community lost them: Drucker, Symonds, Koiter, Massonnet, Sawczuk, König, Martin; in my country Capurso, Ceradini, Gavarini.

But direct methods still represent a fertile research field, still attractive and fashionable, with challenges still open to fruitful and synergistic convergence of structural mechanics, mathematical developments, computational techniques and not only structural engineering, but also diverse technologies. Evidence of such closing remark is provided by this book and by the Athens conference which originated it, and by the sequence of recent meetings and papers collections on direct methods. Colleagues from various research institutions, who promote such initiatives on direct methods and successfully contribute to them, do deserve, in my opinion, the appreciation of the international community of theoretical and applied mechanics.

Technical University (Politecnico), Milan, Italy Giulio Maier 


\section{Preface}

Civil and mechanical engineers are to a large extent concerned with safety- and life assessment of structures under thermo-mechanical loading which may cause severe inelastic straining. This task is virtually impossible to perform following cumbersome and time consuming evolutionary methods which, additionally, require the complete knowledge of the loading history. Mostly, however, only variation intervals of the loads are known. Thus, it is important to be able to produce margins of safe service conditions for structures, as well as for structural material, against excessive inelastic deformations.

Methods that aim towards this end, avoiding step-by-step analysis, are called Direct Methods. They are non-evolutionary, and although such methods have existed for some time, they are attracting an increasing interest from scientists and researchers, based on new mathematical formulations and new developments on numerical analysis.

The present volume contains the most recent advances on these methods. It is the outcome of the third international workshop that was held in Athens on February 2012, following the successful first and second workshops in Aachen in 2007 and Lille in 2009. The event, which attracted more than 30 scientists from 6 countries, was organized by the National Technical University of Athens and was hosted by the Onassis Cultural Center.

The papers in the book are arranged in the order of their appearance in the workshop and their contributions are in the fields of Structural and Soil Mechanics as well as Material Science. All the contributed papers have undergone a rigorous review process before acceptance for publication.

We would like to thank all the scientists that have participated in this book for the high quality level of their work.

We would also like to express our thanks to Professor Giulio Maier, of the Technical University of Milan, for his kindness to foreword this book.

Athens, Greece

Konstantinos Spiliopoulos

Aachen, Germany

Dieter Weichert 


\section{Contents}

Finite Element Limit Analysis and Porous Mises-Schleicher Material . 1 Franck Pastor, Joseph Pastor, and Djimedo Kondo

Limit Analysis: A Layered Approach for Composite Laminates . . . . . . 23 Aurora Angela Pisano, Paolo Fuschi, and Dario De Domenico

Shakedown Analysis of Kinematically Hardening Structures in n-Dimensional Loading Spaces . . . . . . . . . . . . . . . . 57 Jaan-Willem Simon

Computation of Bounds for Anchor Problems in Limit Analysis and Decomposition Techniques . . . . . . . . . . . . . . . . . . . . 79 J.J. Muñoz, N. Rabiei, A. Lyamin, and A. Huerta

Shakedown Analysis of Reissner-Mindlin Plates Using the Edge-Based Smoothed Finite Element Method . . . . . . . . . . . . . . . . . . . . 101 Thanh Ngọc Trần and M. Staat

Progress in Plastic Design of Composites ～. . . . . . . . . . . . . . . . . . 119 Min Chen and Abdelkader Hachemi

The Residual Stress Decomposition Method (RSDM): A Novel Direct Method to Predict Cyclic Elastoplastic States ． . . . . . . . . . . . . 139

Konstantinos V. Spiliopoulos and Konstantinos D. Panagiotou

Use of Layout Optimization to Solve Large-Scale Limit Analysis and Design Problems . . . . . . . . . . . . . . . . . . . . . . . 157

Matthew Gilbert, Colin C. Smith, Samuel J. Hawksbee, and Andrew Tyas

Macroscopic Modeling of Porous Nonassociated Frictional Materials . . . 181 Long Cheng, Géry de Saxcé, and Djimedo Kondo 
Direct Evaluation of the Post-Buckling Behavior of Slender Structures

Through a Numerical Asymptotic Formulation . . . . . . . . . . . . 203

Giovanni Garcea, Antonio Bilotta, Antonio Madeo, and

Raffaele Casciaro

A Quasi-periodic Approximation Based Model Reduction for Limit

Analysis of Micropile Groups ． . . . . . . . . . . . . . . . . . . . . . 229

Zied Kammoun, Joseph Pastor, and Hichem Smaoui

The Anderson-Bishop Problem-Thermal Ratchetting of

a Polycrystalline Metals . . . . . . . . . . . . . . . . . . . . . . . 243

A.R.S. Ponter and A.C.F. Cocks

Recent Development and Application of the Linear Matching Method

for Design Limits in Plasticity and Creep: An Overview . . . . . . . 257

Haofeng Chen and Weihang Chen 